\section{Enhancing Conceptual Knowledge of Energy in Biology with Incorrect Representations}

Ulrike Wernecke, ${ }^{\dagger}$ Kerstin Schütte, ${ }^{\ddagger}$ Julia Schwanewedel, ${ }^{\dagger}$ and Ute Harms ${ }^{\dagger *}$

${ }^{\dagger}$ Department of Biology Education and ₹Department of Educational Research, Leibniz Institute for Science and Mathematics Education (IPN), University of Kiel, 24118 Kiel, Germany

\begin{abstract}
Energy is an important concept in all natural sciences, and a challenging one for school science education. Students' conceptual knowledge of energy is often low, and they entertain misconceptions. Educational research in science and mathematics suggests that learning through depictive representations and learning from errors, based on the theory of negative knowledge, can potentially foster students' knowledge of abstract concepts such as energy. Thus, we propose here an instructional approach that combines these two strategies to foster conceptual knowledge of energy. It involves inserting an error in a biological energy flow diagram, an error that we derived from two prevalent misconceptions about energy: 1) plants get some of their energy from the soil or 2) energy cycles in an ecosystem. The approach's effect on students' conceptual knowledge of energy was tested in an intervention study with pre-post design and 304 ninth grade students $(M=$ 14.79 years). Students who successfully identified and explained the error achieved larger gains in conceptual knowledge than students learning with a correct diagram. Thus, the proposed instructional approach holds promise for improving energy teaching.
\end{abstract}

\section{INTRODUCTION}

Energy is a fundamental conceptual element of all natural phenomena and thus is extremely important in all natural sciences. It also has enormous societal relevance. For example, switching from fossil to renewable energy supplies is crucial for future sustainability, and public acceptance is essential for this transition (World Energy Council, 2015). Therefore, energy is an important topic in both science and general education at school. However, due to its abstractness, the energy concept is highly challenging both to teach and learn. In recent decades, various studies have shown that students have limited knowledge of energy (e.g., Duit, 1984; Trumper, 1993; Opitz et al., 2015) and even advanced students maintain multiple misconceptions (Liu and Tang, 2004; Chabalengula et al., 2012). Thus, there is a clear need for effective instructional tools for fostering development of a sound energy concept.

Such tools could incorporate depictive representations, which can help students to grasp abstract concepts by visualizing phenomena that cannot be seen by the human eye (Ryoo and Linn, 2012). Incorporation of errors could also be potentially beneficial, according to the theory of negative knowledge, which holds that reflecting on errors can lead to a more comprehensive concept of learning content (Oser et al., 1999, 2012). Moreover, educational researchers have demonstrated that reflecting on errors in descriptive representations (i.e., texts and equations) can improve knowledge acquisition (e.g., Booth et al., 2013). Thus, as reported here, we have developed and tested a tool that is intended to foster conceptual knowledge of the abstract scientific concept "energy," based on use of a diagram with a deliberate error rooted in common misconceptions. To elucidate the rationale of our empirical study, we describe in the following section its three theoretical pillars: the energy concept, learning through representations, and learning from errors.
Hannah Sevian, Monitoring Editor

Submitted July 17, 2017; Revised October 27, 2017; Accepted November 8, 2017

CBE Life Sci Educ March 1, 2018 17:ar5 DOI:10.1187/cbe.17-07-0133

*Address correspondence to: Ute Harms (harms@ ipn.uni-kiel.de).

○ 2018 U. Wernecke et al. CBE-Life Sciences Education @ 2018 The American Society for Cell Biology. This article is distributed by The American Society for Cell Biology under license from the author(s). It is available to the public under an Attribution-Noncommercial-Share Alike 3.0 Unported Creative Commons License (http://creativecommons.org/licenses/ by-nc-sa/3.0)

"ASCB®" and "The American Society for Cell Biology $\circledR^{\prime \prime}$ are registered trademarks of The American Society for Cell Biology. 


\section{THEORETICAL BACKGROUND The Energy Concept}

As mentioned earlier, despite being primarily a physical concept, energy is highly important in all natural sciences and many other disciplines (e.g., economics), but here we primarily consider its importance in biological contexts, particularly ecological processes. Diverse biological topics can only be explained by applying the energy concept; for instance, energy is frequently considered when teaching nutrition, photosynthesis, muscle movement, and ecosystems (Needham, 2014; Harms, 2016). The discipline of biology deals with open systems, which follow the physical laws of thermodynamics (Stoy, 2010). In an ecosystem, energy can be transferred to and from the surrounding environment, and although energy cannot be directly measured, the energetic changes in a system can. Disregarding chemosynthesis, the sun is the ultimate energy source for any ecosystem. Its radiation is used by plants to synthesize biological molecules by photosynthesis. That is why plants are the basis of food chains. Food chains then show sequences of trophic levels (i.e., groupings of organisms based on their main source of nutrition). Through feeding relationships, chemical energy is transferred from one trophic level to the next. This transfer of chemical energy, however, accounts for only $\sim 10 \%$ of the energy (Kozlovsky, 1968), which is regarded as the reason why food chains rarely encompass more than five links (Trussell et al., 2006). The reason for the inefficiency of energy transfer through food chains is that every energy transformation in an organism generates thermal energy, which is released to the environment. Moreover, some chemical energy is passed to decomposers, for example, in feces and food waste. Energy cannot be recycled, so a continuous energy input from the sun is needed to sustain the system.

Various studies have shown that students have limited knowledge of the energy concept (e.g., Duit, 1984; Trumper, 1993; Opitz et al., 2015), particularly of principles of energy transfer (e.g., Lin and Hu, 2003; Sadler et al., 2013). Moreover, students have been found to maintain misconceptions about the energy sources of an ecosystem. A popular misconception is that plants get their food or energy from the soil. This belief, which was also disseminated among philosophers and scientists before photosynthesis was discovered (Métioui et al., 2016), is frequently entertained by lower and upper secondary school students (e.g., Boyes and Stanisstreet, 1991; Burger, 2001), and even teachers (Beals et al., 2012). Boyes and Stanisstreet (1991) found that most first-year undergraduate science students surveyed in the United Kingdom knew that plants get energy from the sun, but they often named water, soil, or air as additional sources of energy. Similarly, they often stated that animals get their energy from food, but also from air and water. It seems likely that these students could not distinguish between energy supply and other requirements of plants and animals that are essential for living but do not supply energy (Boyes and Stanisstreet, 1991). Özay and Öztaş (2003) drew the same conclusion from a survey of ninth graders' ideas in Turkey. This is consistent with the finding of Leach et al. (1996) that 16-yearold students in England frequently used the terms "energy," "matter," "food," and "nutrients" interchangeably in the context of ecosystems. DeBoer et al. (2014) found a similar lack of distinction between matter and energy when students in the United States were asked to construct diagrams: some students included the sun in a food web diagram that was supposed to show the transfer of matter, while others did not include the sun in an energy flow diagram. Both students and teachers have been found to believe that energy can be recycled (e.g., by decomposers) and reused (e.g., by plants) in an ecosystem (Burger, 2001; Beals et al., 2012; Lancor, 2014), which also shows confounding of energy flow and matter cycles. Altogether, there is strong evidence that energy is a critical and challenging concept for comprehending fundamental ecological processes. We applied these insights to formulate an error based on common misconceptions to incorporate in our instructional tool (with a depictive representation showing characteristic energy flow through a forest ecosystem) intended to foster conceptual knowledge of energy.

\section{Learning through Representations}

Instruction without using representations (signs that stand for something else) is impossible. Language (spoken or written) and pictures are both external representations but are based on different sign systems. Descriptive representations (texts and mathematical equations) consist of symbols, whereas depictive representations consist of iconic signs (Schnotz and Bannert, 2003). The specific function of depictive representations in science is to visualize phenomena that cannot be seen by the human eye, especially processes on a molecular or cellular level and abstract concepts (Winn, 1989; Kozma and Russell, 2005; Tsui and Treagust, 2013). For example, depictive representations are regarded as helpful for illustrating energy transfer in a food chain by making the abstract process more concrete (Winn, 1989). More recently, intervention studies have provided evidence that depictive representations can help students to grasp aspects of the energy concept. For example, Van Heuvelen and Zou (2001) found that bar chart representations of workenergy processes help university students to understand energy conservation in physics. Similarly, Ryoo and Linn (2012) showed that dynamic and static depictive representations promote middle school students' understanding of energy transformations in photosynthesis. However, as yet we have little evidence about the particular features of representations used in the science classroom that foster understanding of energy.

An analysis of the representation of energy in biology textbooks revealed that flow diagrams with arrows indicating sequences are frequently used to illustrate energetic aspects of photosynthesis, matter cycles, and ecological energy flows (Wernecke et al., 2016). Their abstractness is often lessened through combination with more concrete elements such as schematic drawings, realistic drawings, or photographs. However, representations with such multiple layers are especially demanding: students must both relate the concrete elements to the corresponding things in the real world and decode the meaning of symbols such as arrows (Roth et al., 2005). Moreover, diagrams should include a caption to give an interpretative context (Ametller and Pintó, 2002).

Of course, good representations (of anything) are not sufficient. A requirement for comprehension of a representation is cognitive processing. According to the theory of constructivism and cognitive psychology, the individual builds up an internal, mental representation of the content and connects it with prior knowledge (e.g., Smith et al., 1993; Mayer, 2011). 
Cromley et al. (2010) investigated students' cognitive activities while learning with text and complex biological diagrams. They found that students used a higher proportion of high-level strategies and a lower proportion of low-level strategies when processing diagrams than when processing text. High-level activity is associated with increased comprehension. However, students often just skim over depictive representations and thus fail to exploit their full potential (Cromley et al., 2010). To counteract superficial processing, learners should be given picture-oriented tasks (Weidenmann, 1989).

Kragten et al. (2015) found evidence that prior knowledge is crucial for solving tasks related to flow diagrams ${ }^{1}$ in biology. Therefore, prior knowledge should be activated when students are supposed to learn with such diagrams. Another requirement for learning from diagrams is sufficient knowledge of diagrammatic conventions, as shown by Cheng and Gilbert (2015) specifically for biological flow diagrams. The middle school students surveyed by DeBoer et al. (2014) reportedly had little difficulty interpreting basic graphical representations of ecosystems like flow diagrams. However, two groups of researchers (Barman et al., 1995; Gotwals and Songer, 2010) found that, when middle and high school students in the United States, Australia, and Canada considered a food chain or web, they could describe feeding relationships between the organisms but did not realize that the arrows represented energy transfer in the system. This corroborates the apparent challenges the concept of energy poses for students attempting to understand representations of an ecosystem.

\section{Learning from Errors}

Making errors is a natural part of the learning process. A lot of errors do not occur randomly, but originate from misconceptions (Nesher, 1987). Nevertheless, although errors should be eradicated, different theoretical approaches on learning see them as beneficial for learners when used in a constructive way (Smith et al., 1993). According to the theory of negative knowledge, reflecting on errors can lead to the acquisition of so-called negative knowledge, that is, knowledge of how something is not in contrast to how it really is (Oser et al., 2012; Oser and Spychiger, 2005). Concerning the internal representation of negative knowledge, it seems that incorrect parts of an initial mental model may be labeled as incorrect or as not belonging to this concept and that correct knowledge may be added, resulting in construction of a more comprehensive mental model. Oser and Spychiger (2005) describe negative knowledge as inherent in every piece of knowledge and claim that it serves various functions, inter alia realizing that what seemed correct is not actually correct helps recognition of what is right. In other words, the scope of a concept is sharpened by clarifying what does not belong to it. Thus, certainty is gained, because correct and incorrect conceptions can be more clearly distinguished. Various studies have corroborated the idea that misconceptions may not be extinguished but coexist with scientific conceptions, notably in the context of energy, studies by Liu and Tang (2004) and Solomon (1983). Negative knowledge is assumed to prevent the learner from using the corresponding misconception (Oser and Spychiger, 2005).

${ }^{1}$ Kragten et al. (2015) use the term "process diagram."
A critical issue in this context is that learners' own errors are likely to arouse negative emotions like shame, which may hinder the learning process, so an error-tolerant classroom culture may be crucial for learning from errors in classroom settings (Oser et al., 1999). However, substantially more research is required to clarify such requirements (Steuer and Dresel, 2015). Therefore, it seems reasonable to use constructed errors as a vicarious rather than personal experience in educational contexts. Moreover, learners' own errors occur individually and spontaneously, while the application of constructed errors can be planned. Several studies that have addressed such issues, in various domains, indicate that reflecting on constructed errors promotes acquisition of skills and knowledge. For example, this approach has been used to improve the professional competence of firefighters (Joung et al., 2006) and medical students (Stark et al., 2011), highlighting its cross-domain applicability. In school education, the utility of the approach has been investigated particularly intensively in the domain of mathematics, for example, by inserting an error into the solution of an equation and asking students to state which step was incorrect, why it was wrong, and what must be done to solve the equation correctly. Reflecting on incorrect examples has been shown to improve learners' understanding of mathematical topics such as algebra (Booth et al., 2013), probability (Große and Renkl, 2007), decimal magnitude (Durkin and Rittle-Johnson, 2012), and fractions (Heemsoth and Heinze, 2014).

The effectiveness of learning from errors may depend on the learner's prior knowledge. Students with low prior knowledge benefit more from learning with correct examples, while advanced students learn more from incorrect examples (Heemsoth and Heinze, 2014). Similarly, Große and Renkl (2007) reported that learning with correct and incorrect examples is beneficial for students with high prior knowledge, whereas students with low prior knowledge benefit more from learning with correct examples. Prior knowledge is needed to identify and explain errors. Therefore, highlighting an error lowers the demand on the learner, according to Große and Renkl (2007), who found that students with low prior knowledge profit from support such as highlighted errors. However, in contrast to Große and Renkl (2007), Durkin and Rittle-Johnson (2012) found no indications of an interaction between amount of prior knowledge and either learning with correct examples or learning with correct and incorrect examples.

Students enter the classroom with conceptions resulting from their experience in everyday life. The key feature of learning from errors is that misconceptions can be addressed by errors to prevent students from using them (Oser and Spychiger, 2005). Aside from incorrect equations in mathematics, it has been shown that learning from science texts that explicitly address misconceptions (so-called refutation texts) effectively fosters positive learning outcomes (e.g., Özkan et al., 2004; Tippett, 2010). Refutation texts require simultaneous activation of correct and incorrect conceptions, which helps learners to become aware of the inconsistency between the misconception and the scientific conception. This is a crucial step toward conceptual change (Posner et al., 1982; Van den Broek and Kendeou, 2008). Refutation texts have been successfully applied in the context of energy (Diakidoy et al., 2003).

To date, descriptive representations (i.e., texts and equations) have been mainly used in material designed to implement this 
approach. However, given the importance of depictive representations in communicating scientific concepts and facilitating the development of correct mental models of these concepts, a significant challenge for researchers is to "design visualizations that specifically target ... faulty beliefs" (Rapp, 2005, p. 56).

\section{THE ERROR-BASED PICTORIAL TOOL TO FOSTER CONCEPTUAL KNOWLEDGE OF ENERGY}

Depictive representations of abstract science concepts have proven advantageous for learning about energy. Moreover, educational research in mathematics has shown that learning from errors in descriptive representations can potentially foster students' knowledge of abstract concepts. We hypothesized that combining the learning from errors approach with learning through depictive representations - an error-based pictorial tool-would promote knowledge acquisition about the abstract concept energy more so than learning with a correct representation. Our underlying assumption was that alerting students to the fact that an error had been deliberately placed in a diagram would encourage them to examine the representation more thoroughly, rather than skimming over it. If so, learning with diagrams incorporating deliberate errors should foster acquisition of conceptual knowledge of energy more effectively than learning with a correct representation. This is because, as previously stated, addressing common errors that are rooted in misconceptions may promote learning by making negative knowledge explicit.

Hence, in the intervention study reported here, we inserted an error in an energy-related diagram that showed the energy flow through a simple food chain in a typical ecosystem. This context was chosen for two reasons. First, energy flow is an important topic in biology and comprehending it requires sound understanding of the energy concept. Second, there is well-documented evidence that students possess prevalent misconceptions regarding this topic. Our empirical study addressed one hypothesis and four explorative research questions:

Hypothesis: On the basis of the findings of several studies on learning in mathematics (as described in the previous section), we hypothesize that learning with an incorrect representation would foster acquisition of conceptual knowledge of energy more effectively than learning with a correct representation.

Research question 1: Do students learn more when the error has already been encircled in the diagram when they receive it, or when they have to identify it by themselves? Concerning the underlying mode of action, trying to identify the error may encourage students to examine each part of the diagram thoroughly. However, failing to identify the error may be a barrier to learning, as students might continue to believe that the incorrect feature is correct or they might assume that a correct feature is incorrect.
Research question 2: Does students' amount of prior knowledge influence how much conceptual knowledge of energy they gain?

Research question 3: What features of the diagram do students consider to be incorrect besides the deliberate error (an energy backflow arrow)?

Research question 4: What explanations do students give for the encircled error?

\section{METHODS}

\section{Procedure and Sample}

An intervention study with pre/posttest design and three experimental groups was conducted. Students' conceptual knowledge was assessed before and after an intervention; the design thus allows gauging differential change of conceptual knowledge between conditions (i.e., effects of the intervention). The three groups differed in received learning material, which consisted of three variants of a diagram (one correct; one with an encircled error; and one with that same error, but not encircled) showing energy flow through a forest ecosystem and associated tasks (see Table 1 and Figure 1).

The study was conducted by U.W. and a trained university student. The pretest was administered 2 weeks before the intervention. Although the topic should already have been treated in biology classes, the intervention started for all groups with a standardized presentation on energy flow in ecosystems to ensure that all students were provided with the essential information to identify and explain the error (see the Supplemental Material). Afterward, students received their respective learning material (see Table 1), which they worked on independently. In an effort to minimize class effects, all three variants of the material were distributed almost equally in each class. During the seatwork, students could use printouts of slides of the presentation. After students were finished, slides and learning material were collected by the administrator. Students then completed the posttest. At the close of the session, the administrator fully debriefed the students and also provided standardized information about correct solutions of the tasks. Teachers were not directly involved in conducting the study.

Power analyses with G*Power 3.1 (Faul et al., 2009) indicated that, for one-way analysis of variance (ANOVA) and a middle effect size of $f=0.25$, a sample size of $N=252$ students would be required. To meet this requirement, we recruited 325 ninth graders from 12 secondary schools on the highest track of the ability-grouped German school system ("Gymnasium") to participate in the study. However, 15 students missed the second measurement occasion and were excluded from the sample. Another six students were not compliant, as they did not work on the diagram tasks or the posttest. Thus, the remaining sample comprised 304 students

TABLE 1. Learning materials provided to the three groups

\begin{tabular}{ll}
\hline Group 1 & \multicolumn{1}{c}{ Group 2 } \\
\hline Incorrect diagram, without the error encircled & Incorrect diagram, with the error encircled \\
- Identify the error & $\bullet$ Explain the error \\
- Explain the error & $\bullet$ Explain energy flow \\
- Explain energy flow & \\
\hline
\end{tabular}




\section{Energy flow through a forest ecosystem}

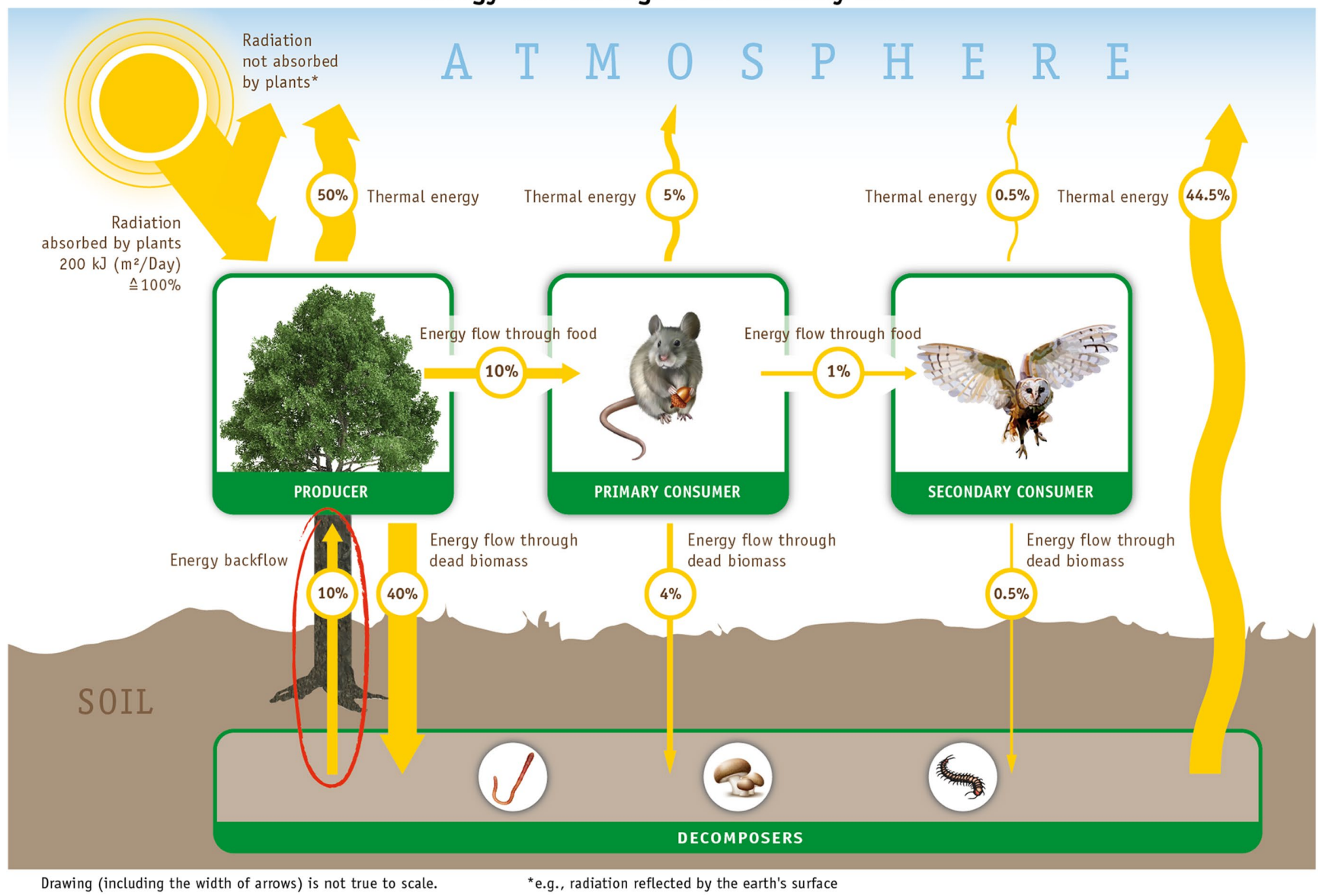

FIGURE 1. Incorrect diagram with encircled error (provided to group 2).

(52.2\% female; $\mathrm{M}=14.79$ years, $\mathrm{SD}=0.48$ years): 102,100 , and 102 in groups 1, 2, and 3, respectively.

\section{Materials and Instruments}

On the basis of the energy flow diagrams in textbooks surveyed by Wernecke et al. (2016) and flow diagrams of textbooks not surveyed there (e.g., Beyer et al., 2010; Markl, 2010; Braun et al., 2011), we designed the energy flow diagram shown in Figure 1. This diagram is a depiction of the energy transfer processes in an ecosystem, which cannot be observed directly due to temporal and spatial constraints. The diagram includes realistic drawings of organisms as representatives of trophic levels and contains labels, an identifying headline, and a caption concerning the scale. The indicated percentages are approximations. To reduce complexity, we applied two simplifications compared with typical energy flow diagrams in textbooks. First, we chose to portray the radiation from the sun as being only split into radiation that is not absorbed by plants (e.g., radiation reflected by the earth's surface, as explained in an additional caption; some textbooks differentiate between reflected and thermally dissipated energy) and radiation absorbed by plants (set to $100 \%$ of the energy entering the system). Second, the chosen food chain "tree $\rightarrow$ mouse $\rightarrow$ eagle owl" consists of only three trophic levels, whereas many other flow diagrams show four or five trophic levels. How- ever, all energy pathways can be traced in the reduced version, and the principles of energy flow are fully delineated.

The error inserted into the incorrect versions of the energy flow diagram targets widespread misconceptions. This is an additional arrow from the decomposers in the soil to the producers, suggesting that plants get some of their energy from the soil (Boyes and Stanisstreet, 1991; Leach et al., 1996). This arrow implied that energy, just like matter, flows in a cycle and can be recycled (Burger, 2001; Beals et al., 2012; Lancor, 2014). Three versions of the diagram were designed and complemented with tasks, as described and shown in Table 1 and the Supplemental Material.

The students' conceptual knowledge of energy was assessed by a test with 18 items. These included eight multiple-choice items (regarded as representative in terms of context, difficulty, and discrimination) from the test developed to assess students' general understanding of energy and validated by Opitz et al. (2017). The other 10 items (eight multiple-choice and two open-ended items) specifically concern energy flow. Three of these items were newly created, while the others were compiled, with some modification, from sources shown in the Supplemental Material. Despite pretesting before the study, internal consistency was low for the pretest ( $\alpha=0.57$ ), but acceptable for the posttest $(\alpha=0.71)$. 
The following control variables were also assessed: cognitive abilities, using the N2 scale (graphic analogies) of the Kognitiver Fähigkeitstest (KFT) cognitive ability test (Heller and Perleth, 2000); effort appraised on a 10-point scale (Organisation for Economic Co-operation and Development, 2010); and time spent on tasks, the pretest, and the posttest. Moreover, each student completed a form reporting his or her sex, age, and biology mark on the last report card.

\section{Data Preparation and Analysis}

All test items were coded dichotomously. The objectivity of the ratings concerning the two items with an open-ended answer format was checked by rerating $25 \%$ of the posttest answers (72 and 69, respectively). Cohen's kappa was chosen as a chancecorrected coefficient of rater agreement (Cohen, 1960); it indicated at least substantial agreement $(\kappa=0.96$ and 0.76 , respectively; Landis and Koch, 1977). To address our hypothesis and research questions 1 and 2, we conducted mixed-model ANOVAs using SPSS 23, and computed a latent difference score model using Mplus 7.

To address research questions 3 and 4, we investigated students' performance on the diagram tasks using descriptive statistics, focusing on the identification and explanation of the error by participants in groups 1 and 2 . For a check of the objectivity of the ratings, $25 \%$ (26 in each case) of the explanations of students in groups 1 and 2 were randomly selected and coded by a second rater. The Cohen's kappa values of the ratings of groups $1(\kappa=0.87)$ and $2(\kappa=0.63)$ indicated almost perfect and substantial rater agreement, respectively (Landis and Koch, 1977). Differences between means were regarded as significant if $p<0.05$.

\section{RESULTS}

Initially, to ascertain that randomly distributing students to groups did not result in meaningful differences between the groups we conducted a set of one-way ANOVAs. Students' pretest scores, indicating their prior knowledge, did not significantly differ between the three groups, $F(2,286)=0.69, p=$ 0.500 (cf. Table 2). Moreover, there were no significant differences between the three groups of students in time spent on the pretest, posttest, and working with the diagram, $F$ values $<2.70, p$ values $>0.05$. Similarly, no significant differences were observed between the three experimental groups in

TABLE 2. Means (and standard deviations) of control variables

\begin{tabular}{lccc}
\hline & Group 1 & Group 2 & Group 3 \\
\hline $\begin{array}{l}\text { Pretest score (prior } \\
\quad \text { knowledge) }\end{array}$ & $6.96(2.69)$ & $6.56(2.99)$ & $6.99(2.67)$ \\
$\begin{array}{l}\text { Working time: pretest } \\
\quad(m i n)\end{array}$ & $22.67(5.14)$ & $24.07(5.02)$ & $24.06(3.91)$ \\
$\begin{array}{l}\text { Working time: posttest } \\
\quad(m i n)\end{array}$ & $16.47(4.49)$ & $16.65(4.47)$ & $16.86(3.98)$ \\
$\begin{array}{l}\text { Working time: diagram } \\
\quad(m i n)\end{array}$ & $15.86(5.27)$ & $15.46(4.66)$ & $16.01(5.34)$ \\
$\begin{array}{l}\text { Cognitive abilities } \\
\text { Biology grade }\end{array}$ & $18.95(3.60)$ & $19.13(3.93)$ & $18.75(3.96)$ \\
Effort & $2.35(0.79)$ & $2.46(0.71)$ & $2.38(0.75)$ \\
\hline
\end{tabular}

${ }^{a}$ The German grading system has a numerical 1-6 format, in which 1 is the highest and 6 the lowest grade. cognitive abilities, last report card mark in biology, or effort, $F$ values $<1.73$, $p$ values $>0.05$

Descriptive statistics showed that only $n=11$ (10.8\%) of the students in group 1 identified the incorrect arrow in the diagram and satisfactorily explained why it was incorrect, while $n$ $=28(28 \%)$ of the students in group 2 satisfactorily explained why the encircled arrow was incorrect. Because students were not informed about the correct solution before the posttest, students who failed to find and explain the error had no opportunity to build up a contrast between correct and incorrect knowledge. We further split groups 1 and 2 into two subgroups of students (total number of groups $=4$ ), those who did and those who did not solve their respective tasks, thereby forming five sets with the students of group 3. With these five groups, we conducted another one-way ANOVA to investigate whether prior knowledge played a role in whether or not students solved their respective tasks; differences in the pretest scores were indeed statistically significant, $F(4,284)=2.73, p=$ 0.029 . Assessment of pairwise differences between the sets by post hoc tests with Bonferroni correction revealed one significant difference: the successful students in group 2 had a higher pretest score $(\mathrm{M}=7.89)$ than students who failed in this group $(\mathrm{M}=6.00), p=0.024$. One-way ANOVA also detected a significant difference between the five sets in effort, $F(4,294)=$ 4.294, $p=0.020$, but post hoc tests with Bonferroni correction detected no significant difference between any pairs of sets in this respect.

To evaluate our hypothesis that learning with an incorrect representation fosters acquisition of conceptual knowledge of energy more effectively than learning with a correct representation, we conducted a one-way repeated-measures ANOVA, again initially with the three experimental groups. The main effect of measurement occasion shows that test results increased substantially from pre- to posttest, $F(1,285)=233.48, p<$ $0.001, \eta_{\mathrm{p}}^{2}=0.450$. However, the interaction effect did not indicate differential improvement of students' knowledge of the energy concept between the three groups, $F(2,285)=2.43$, $p=$ $0.090, \eta_{\mathrm{p}}^{2}=0.017$. The main effect of group was not significant, $F(2,285)=0.17, p=0.842, \eta_{\mathrm{p}}^{2}=0.001$. This also implies that encircling the error in the incorrect representation did not result in higher or lower knowledge gain than use of the same learning material without the presumed support offered by encircling it (research question 1).

However, when we conducted the one-way repeated-measures ANOVA comparing the five (sub)groups of students, in addition to the significant main effect of measurement occasion, $F(1,283)=199.92, p<0.001, \eta_{p}^{2}=0.414$, there was an interaction effect indicating differential improvement of knowledge of the energy concept, $F(4,283)=5.94, p<0.001$, $\eta_{\mathrm{p}}^{2}=0.077$. Post hoc tests with Bonferroni correction revealed that students in group 2 who provided a sufficient explanation of the error learned significantly more than students in that group who did not $(p<0.001)$. They also learned more than the students who failed to identify and explain the error in group 1 and more than students in group $3(p=0.003$ and 0.029 , respectively). Differences between the other pairs of sets were not significant (Table 3).

To assess the relationship between pretest scores and knowledge gain (research question 2) and investigate the robustness of our results across analytical approaches, we also analyzed 
TABLE 3. Means and standard deviations of energy test score gains

\begin{tabular}{lccc}
\hline Group & $\boldsymbol{n}$ & M & SD \\
\hline Group 1 & 96 & 2.07 & 0.27 \\
$\quad$ Successful & 11 & 4.64 & 0.74 \\
$\quad$ Failed & 85 & 1.74 & 0.27 \\
Group 2 & 93 & 2.82 & 0.29 \\
$\quad$ Successful & 28 & 4.11 & 0.43 \\
$\quad$ Failed & 65 & 2.46 & 0.36 \\
Group 3 & 99 & 2.44 & 0.28 \\
\hline
\end{tabular}

the data using latent difference score models in Mplus. Corroborating results from the ANOVAs, this showed that posttest scores were significantly higher than pretest scores $(p<0.001)$. Wald $\chi^{2}(W)$ tests of parameter equality indicated that there were no significant differences in the improvement of students' knowledge between groups 1 and $3, W(1)=0.92, p=0.339$, or between groups 2 and $3, W(1)=1.87, p=0.339$, but students in group 2 learned significantly more than students in group 1 , $W(1)=5.61, p=0.018$.

We then used a latent difference score model to assess differences between students of group 1 who did and did not identify and explain the error. A Wald test indicated that the successful students improved their conceptual knowledge of energy significantly more than students who failed to solve their task, $W(1)=14.83, p<0.001$. More importantly, students in group 1 who solved their task also gained significantly more knowledge of energy than students in group 2, who learned with the marked error, $W(1)=4.92, p=0.027$, and group 3, who learned with the correct diagram, $W(1)=8.57$, $p=0.003$. Similarly, successful students of group 2 who provided a satisfactory explanation of the error learned significantly more than students in group 2 who failed, $W(1)=8.83$, $p=0.003$. They also learned more than the students who failed to identify and explain the error in group $1, W(1)=22.85, p<$ 0.001 , and students in group $3, W(1)=11.21, p=0.001$. The knowledge gains of successful students in groups 1 and 2 were not significantly different, $W(1)=0.41, p=0.521$. Moreover, knowledge gains of students who failed in groups 1 and 2, and students in group 3 were not significantly different ( $p$ values $>$ 0.05 ). Hence, our hypothesis that learning with an incorrect representation fosters acquisition of conceptual knowledge of energy more effectively than learning with a correct representation was supported for students who identified and explained the error.

Wald tests also revealed that the successful students of group 1 self-reportedly put more effort into work with the diagram than students of their group who did not identify and satisfactorily explain the error, $W(1)=6.98, p=0.008$. No such difference in effort between successful and unsuccessful students was found in group $2, W(1)=3.10, p=0.078$.

Regarding research question 2, the correlations between pretest score and change score in all groups and subgroups were significantly negative ( $r$ values $=-0.215$ to $-0.559, p$ values $<0.05$ ), except for students who successfully explained the error in group $2(r=-0.253, p=0.153)$. Thus, the increase in students' conceptual knowledge of energy was higher in all (sub)groups the less prior knowledge they brought to their respective tasks.

\section{Task Performance}

To address research questions 3 and 4, we investigated students' performance on the diagram tasks.

Group 1 ( $n=102)$-Incorrect Diagram without the Error Encircled. Only 11 students (10.8\%) in group 1 correctly identified the incorrect arrow and satisfactorily explained why it was incorrect. Another eight students (7.8\%) marked it correctly but gave an inadequate or no explanation. Most of the students in the group $(n=69,67.6 \%)$ marked one of the following features of the diagram.

1. The arrow indicating energy flow through food from the mouse to the eagle owl (39.3\% of the incorrect markings). Most of the students who selected this feature stated that the accompanying percentage should be $10 \%$ rather than $1 \%$, failing to grasp that the percentages referred to percentages of the original amount of energy entering the system that are transferred between the trophic levels: "Then there are the secondary consumers. Here, again 10\% of the energy is transferred. At this spot, there is an error in the diagram, because the mouse does not pass on just $1 \%$ of its energy."

2. The arrow indicating dissipation of thermal energy from the decomposers to the atmosphere $(27.9 \%$ of the incorrect markings). Students marking this arrow as incorrect usually noticed the inconsistency between the amounts of energy flowing to and from the decomposers, but they considered the energy backflow arrow to be correct and changed the percentage associated with the thermal energy arrow: "If you sum it up, you get that the decomposers have $44.5 \%$ of the energy. However, decomposers pass $10 \%$ to the producers and thus can emit just $34.5 \%$ of the thermal energy."

3 . The arrow indicating energy flow through dead biomass from the eagle owl to the decomposers (16.4\% of the incorrect markings). Some students who marked this as incorrect argued that the accompanying percentage should be $0.4 \%$ to continue the sequence of percentages of energy flow through dead biomass. "On the sheet, the value of $0.5 \%$ is false, because the number gets consistently smaller by a zero point $\rightarrow 40 \% \rightarrow 4 \% \rightarrow 0.4 \%$ so there should be nothing with a $5 . "$

4. The arrow indicating dissipation of thermal energy from the producers to the atmosphere (4.9\% of the incorrect markings). ${ }^{2}$ Students who selected this feature expressed the belief that plants do not give thermal energy to the environment: "The tree does not release thermal energy because it does not move."

The remaining students marked another detail in addition to the incorrect arrow (three students, 2.9\%), or either made an ambiguous marking or no marking at all $(n=11,10.8 \%){ }^{3}$

Group 2 ( $n=100)$-Incorrect Diagram with the Error Encircled. Twenty-eight (28\%) students in group 2 sufficiently explained why the encircled arrow was incorrect, by referring either to plant nutrition (plants do not get energy from the soil

${ }^{2}$ The remaining $11.5 \%$ of the incorrect markings refer to various other features in the diagram.

${ }^{3}$ The sum of $99.9 \%$ is caused by rounding. 
or the decomposers/plants only get energy from the sun) or general characteristics of energy flow (energy cannot be recycled/energy does not flow in a cycle). Most students ( $n=63$, $63.0 \%)$ gave an unsatisfactory explanation. The most frequent statement (39.7\%) was that plants get energy from the soil, but the percentage accompanying the arrow was too high or too low, for example, "The marked feature is false because the consumer [sic] must absorb 100\%."

Additionally, a considerable number of students (27.0\%) said that no energy would be left for backflow. These students noticed the inconsistency between the energy flowing to the decomposers and being released from them: "The decomposers cannot give $10 \%$ of the energy back to the producers, because they get a total of $44.5 \%$ of the energy from the food chain, but these $44.5 \%$ are lost by thermal energy. Thus, they do not have energy left they could hand over to the producers." ${ }^{4}$ However, a solely mathematical argument was not considered a sufficient explanation.

A few other students stated that the arrow is correct $(n=2$, 2.0\%): "The red marked area is not a mistake as decomposers as well as consumers cannot produce their own energy. However, they give off part of the food they received previously. This part transferred to the tree, amounts to generally $10 \%$ of the received energy." The remaining seven students (7\%) did not give any explanation at all.

Group 3 ( $n=103)-$ Correct Diagram. Students in group 3 described the correct diagram. Their texts were not analyzed further in the context of this study.

\section{DISCUSSION}

The instructional tool presented and considered here integrates the approaches of learning from errors and learning through depictive representations, by incorporating a pictorial error based on well-known misconceptions of the flow of energy derived from the literature. The tool was used to explore whether learning with an incorrect flow diagram enhances students' conceptual knowledge of energy more than learning with a correct diagram. The results indicate that learning from such errors fosters acquisition of conceptual knowledge of energy more effectively than learning with a correct diagram, provided that the students succeed in (identifying and) explaining the error. Failure to perform associated tasks adequately does not seem to be particularly harmful, as students who failed to identify and explain the error did not gain less knowledge than students learning with the correct diagram. Strikingly, only $11 \%$ of students who learned with the incorrect diagram (group 1) and $28 \%$ of students who learned with the incorrect diagram with encircled error (group 2) satisfactorily completed their respective tasks. Successful and unsuccessful students did not significantly differ in cognitive abilities or biology grade. However, successful students in group 1 self-reportedly put more effort into work with the diagram than those who failed. This indicates that identifying the error may be especially demanding, as each part of the diagram must be examined thoroughly, and students must take the task seriously. However, generally, students learning with an incorrect diagram did not reported

${ }^{4}$ The remaining $33.3 \%$ of explanations do not fit into any of the mentioned categories. making more effort than those learning with a correct diagram. The effort might have been influenced by study-related factors that were equal in all groups (and not present in regular lessons), for instance, the extraordinary situation or the fact that the results would not affect the students' biology grade.

Concerning the relevance of prior knowledge, there was no statistically significant difference in pretest scores (and thus assumed prior knowledge) between successful and unsuccessful students in group 1, but this could be due to the small proportion of successful students (11\%), and consequent low statistical power. Moreover, successful students in group 2 had a higher mean pretest score than those who failed. This finding supports the assumptions that prior knowledge is needed to identify and explain the error, and highlighting errors reduces demands on learners (Große and Renkl, 2007). Research on learning with correct worked examples also shows that learners' prior knowledge should be considered when selecting prompts intended to evoke self-explanations (Neubrand et al., 2016; Neubrand and Harms, 2017). Thus, matches between instructional support and learners' prior knowledge are crucial for learning with both correct and incorrect learning material. We conclude that both learning with correct worked examples in combination with prompts and learning from errors enhances cognitive activation of the learner, because both address students' prior knowledge (Baumert et al., 2010).

In contrast to patterns typically observed in mathematics education, correlations between pretest scores and knowledge gains were negative in all groups. Learning from the incorrect diagram showing energy flow through a forest ecosystem benefited students with low prior knowledge, implying that our approach is not solely applicable to high-achieving students. The higher students scored on the pretest, the lower the conceptual knowledge of energy they gained during the intervention. However, this finding is not the result of a ceiling effect in the energy test. It is possible that students in group 1 stopped examining the diagram once they thought they had identified the incorrect feature, thus forfeiting the chance to further advance their knowledge. Hence, not specifying the number of errors inserted in the diagram might be advantageous. This might be a crucial difference from learning from errors in mathematics education, where students usually have to solve problems correctly, and thus have to examine complete representations.

Große and Renkl (2007) and Heemsoth and Heinze (2014) found that students with high prior knowledge benefit more from learning with incorrect learning material than students with low prior knowledge, whereas Durkin and Rittle-Johnson (2012) found no such difference. We found the opposite pattern, but our results clearly showed a need for high prior knowledge to identify and explain the error. This is not surprising, because, as exemplified in the theoretical background, prior knowledge of the content and about diagrammatic conventions is needed to learn successfully with biological diagrams (Cheng and Gilbert, 2015; Kragten et al., 2015). Considering the various features in the diagram that were erroneously identified as incorrect by the students in group 1, we found little evidence of difficulties with diagrammatic conventions such as arrows, spatial relationships, and colors. However, we detected content-related difficulties. The feature identified most frequently as incorrect-the arrow indicating energy flow from the mouse to the eagle owl-was erroneously regarded as incorrect due to 
misunderstanding of the percentages of energy flowing into the system. We decided to include percentages in the diagram for two reasons. First, energy can be conceptualized as an abstract accounting quantity defined in a system (Duit, 2014). For example, the given percentages illustrate that energy is finally transferred to the atmosphere, thereby indicating that an ecosystem depends on a constant energy source. Second, percentages are typical features of energy flow diagrams in biology textbooks. However, they also gave students a clue about the error and offered them the possibility to argue mathematically (e.g., "There is no energy left for backflow") instead of biologically (e.g., "Plants do not get energy from the soil"). Thus, the students may have expected to find a small error in the numbers, rather than considering a whole arrow to be incorrect. To counter this potential learning obstacle, a diagram without percentages, representing the error solely in depictive information, could be used in future studies.

Interpreting the results, it should be noted that the set tasks and correct responses were discussed only after the posttest. In an authentic class setting, discussion of such an error would be a crucial step of the instructional process to ensure that misconceptions are not reinforced. Students who do not identify and explain the error, and thus do not establish the contrast between correct and incorrect knowledge by themselves, must be confronted with the correct knowledge through discussion to facilitate learning.

\section{Limitations}

The study presented here has several methodological limitations. First, despite pilot tests, the internal consistency of the energy test was rather low, especially for the pretest. Second, a follow-up test of students' knowledge of the energy concept, assessing whether the differential knowledge gain is maintained, would be instructive (i.e., investigation of the sustainability). Third, analysis of the learning of a group without a diagram would have allowed estimation of the knowledge gain induced by the presentation alone. However, we decided to settle for assessing the learning from errors approach in relation to comparable instruction in terms of the arrangement (individual work) and time spent on tasks. Fourth, systematically implementing the error-based pictorial tool in ecology instruction across participating classes was not practical (especially because of schools' internal curricula). Given these limitations, the study should be regarded as a first step toward combining learning from errors and depictive representations, particularly in biological energy contexts.

\section{Implications for Instruction and Future Research}

Identifying and reflecting errors, thereby establishing a contrast between positive and negative knowledge, requires prior knowledge. Therefore, a depictive instructional tool incorporating an incorrect representation should not be used to introduce a new concept or topic. Moreover, teachers should ensure that all students are eventually provided with the positive knowledge, for example, by thoroughly discussing the tasks and correct responses in the classroom.

The learning from errors approach has not yet found its way into school teaching; correct examples are mainly used in classrooms (Booth et al., 2013). Therefore, more practical teaching material implementing the approach is needed. In this study, a biological flow diagram was used, partly because this type of representation is frequently (and advantageously) used to depict energy flows in biological and ecological systems. Further studies should investigate whether learning from errors is transferable to other types of depictive representations and other scientific domains. Ideally, inserted errors should address prevalent misconceptions, and the students must have sufficient prior knowledge of the conventions of the type of representation used. We also need to learn more about the role of prior knowledge in learning from errors in different domains and from different representations, given the heterogeneous research results. Moreover, a sociosemiotics perspective (e.g., Kress and van Leeuwen, 1990) might provide valuable insights for the use of incorrect depictive representations in science teaching.

A potentially harmful effect of presenting students with incorrect representations is that they may memorize their content. Several studies have shown that, when conflicting information is presented in picture and text, students are more inclined to remember the information embedded in the picture (Peeck, 1989; Crisp and Sweiry, 2006). Hence, future studies should include a follow-up test to assess this potential risk and the sustainability of students' knowledge acquisition. Moreover, closer examination of strategies that students use while looking for errors in a picture is warranted and could lead to the design of supporting provisions besides marking the error. For this purpose, process-oriented studies using eye-tracking methodology and think-aloud protocols might prove valuable.

According to the theory of negative knowledge and preliminary empirical studies, an error-tolerant classroom culture is needed for students to learn from their own errors (Oser et al., 1999; Steuer and Dresel, 2015). Instructions concerning deliberately introduced errors might contribute to a constructive error climate by illustrating that it is possible and desirable to use errors as opportunities for learning. Beyond the direct effect on students' knowledge about abstract concepts such as energy, this instructional approach might thus enhance science teaching more generally.

\section{ACKNOWLEDGMENTS}

We thank the journal reviewers for their detailed and helpful recommendations. This work was supported by the European Science Education Research Association (ESERA) with an Early Career Researcher Travel Award 2016.

\section{REFERENCES}

Ametller, J., \& Pintó, R. (2002). Students' reading of innovative images of energy at secondary school level. International Journal of Science Education, 24, 285-312. doi: 10.1080/09500690110078914

Barman, C. R., Griffiths, A. K., \& Okebukola, P. A. O. (1995). High school students' concepts regarding food chains and food webs: A multinational study. International Journal of Science Education, 17, 775-782. doi: 10.1080/0950069950170608

Baumert, J., Kunter, M., Blum, W., Brunner, M., Voss, T., Jordan, A., ... Tsai, Y M. (2010). Teachers' mathematical knowledge, cognitive activation in the classroom, and student progress. American Educational Research Journal, 47, 133-180. doi: 10.3102/0002831209345157

Beals, A. M., McNall Krall, R., \& Wymer, C. L. (2012). Energy flow through an ecosystem: Conceptions of in-service elementary and middle school teachers. International Journal of Biology Education, 2, 1-18. 
Beyer, I., Remé, R., \& Steinert, C. (Eds.). (2010). Natura 2. Biologie für Gymnasien [Natura 2. Biology for secondary schools]. Stuttgart, Germany: Klett.

Booth, J. L., Lange, K. E., Koedinger, K. R., \& Newton, K. J. (2013). Using example problems to improve student learning in algebra: Differentiating between correct and incorrect examples. Learning and Instruction, 25, 24-34. doi: 10.1016/j.learninstruc.2012.11.002

Boyes, E., \& Stanisstreet, M. (1991). Misconceptions in first-year undergraduate science students about energy sources for living organisms. Journal of Biological Education, 25, 209-213. doi: 10.1080/00219266.1991.9655208

Braun, J., Paul, A., \& Westendorf-Bröring, E. (Eds.). (2011). Biologie heute SII [Biology today for upper secondary school]. Braunschweig, Germany: Westermann Schroedel.

Burger, J. (2001). Schülervorstellungen zu "Energie im biologischen Kontext." Ermittlungen, Analysen und Schlussfolgerungen [Student conceptions concerning energy in biological contexts. Research, analysis, and conclusions] (PhD Dissertation). University of Bielefeld, Bielefeld, Germany. Retrieved from pub.uni-bielefeld.de/download/2305865/2305868

Chabalengula, V. M., Sanders, M., \& Mumba, F. (2012). Diagnosing students understanding of energy and its related concepts in biological contexts International Journal of Science and Mathematics Education, 10, 241 266. doi: 10.1007/s10763-011-9291-2

Cheng, M. M. W., \& Gilbert, J. K. (2015). Students' visualization of diagrams representing the human circulatory system: The use of spatial isomorphism and representational conventions. International Journal of Science Education, 37, 136-161. doi: 10.1080/09500693.2014.969359

Cohen, J. (1960). A coefficient of agreement for nominal scales. Educational and Psychological Measurement, 20, 37-46. doi: 10.1177/ 001316446002000104

Crisp, V., \& Sweiry, E. (2006). Can a picture ruin a thousand words? The effects of visual resources in exam questions. Educational Research, 48, 139-154. doi: 10.1080/00131880600732249

Cromley, J. G., Snyder-Hogan, L. E., \& Luciw-Dubas, U. A. (2010). Cognitive activities in complex science text and diagrams. Contemporary Educational Psychology, 35, 59-74. doi: 10.1016/j.cedpsych.2009.10.002

DeBoer, G. E., Quellmalz, E. S., Davenport, J. L., Timms, M. J., Herrmann-Abell, C. F., Buckley, B. C., ... Flanagan, J. C. (2014). Comparing three online testing modalities: Using static, active, and interactive online testing modalities to assess middle school students' understanding of fundamenta ideas and use of inquiry skills related to ecosystems. Journal of Research in Science Teaching, 51, 523-554. doi: 10.1002/tea.21145

Diakidoy, I.-A. N., Kendeou, P., \& loannides, C. (2003). Reading about energy: The effects of text structure in science learning and conceptual change. Contemporary Educational Psychology, 28, 335-356. doi: 10.1016/ s0361-476x(02)00039-5

Duit, R. (1984). Learning the energy concept in school-Empirical results from the Philippines and West Germany. Physics Education, 19, 59-66 doi: 10.1088/0031-9120/19/2/306

Duit, R. (2014). Teaching and learning the physics energy concept. In Chen, R. F., Eisenkraft, A., Fortus, D., Krajcik, J., Neumann, K., Nordine, J., \& Scheff, A. (Eds.), Teaching and learning of energy in $K-12$ education (pp. 67-85). New York: Springer

Durkin, K., \& Rittle-Johnson, B. (2012). The effectiveness of using incorrect examples to support learning about decimal magnitude. Learning and Instruction, 22, 206-214. doi: 10.1016/j.learninstruc.2011.11.001

Faul, F., Erdfelder, E., Buchner, A., \& Lang, A. G. (2009). Statistical power analyses using G*Power 3.1: Tests for correlation and regression analyses. Behavioral Research Methods, 41, 1149-1160. doi: 10.3758/ BRM.41.4.1149

Gotwals, A. W., \& Songer, N. B. (2010). Reasoning up and down a food chain: Using an assessment framework to investigate students' middle knowledge. Science Education, 94, 259-281. doi: 10.1002/sce.20368

Große, C. S., \& Renkl, A. (2007). Finding and fixing errors in worked examples: Can this foster learning outcomes? Learning and Instruction, 17, 612634. doi: 10.1016/j.learninstruc.2007.09.008

Harms, U. (2016). Ohne Energie geht nichts! [Nothing works without energy]. Unterricht Biologie, 411, 2-11.

Heemsoth, T., \& Heinze, A. (2014). The impact of incorrect examples on learning fractions: A field experiment with 6 th grade students. Instructional Science, 42, 639-657. doi: 10.1007/s11251-013-9302-5
Heller, K. A., \& Perleth, C. (2000). KFT 4-12 +R-Kognitiver Fähigkeits-Test für 4.-12. Klassen, Revision [Test of cognitive abilities in grades 4-12, revised]. Göttingen, Germany: Hogrefe.

Joung, W., Hesketh, B., \& Neal, A. (2006). Using "war stories" to train for adaptive performance: Is it better to learn from error or success? Applied Psychology, 55, 282-302. doi: 10.1111/j.1464-0597.2006.00244.x

Kozlovsky, D. (1968). A critical evaluation of the trophic level concept. I. Ecological efficiencies. Ecology, 49, 48-60. doi: 10.2307/1933560

Kozma, R., \& Russell, J. (2005). Students becoming chemists: Developing representational competence. In Gilbert, J. K. (Ed.), Visualization in science education (pp. 121-146). Dordrecht, Netherlands: Springer.

Kragten, M., Admiraal, W., \& Rijlaarsdam, G. (2015). Students' ability to solve process-diagram problems in secondary biology education. Journal of Biological Education, 49, 91-103. doi: 10.1080/00219266.2014 888363

Kress, G., \& van Leeuwen, T. (1990). Reading images. Geelong, Australia: Deakin University Press.

Lancor, R. (2014). Using student-generated analogies to investigate conceptions of energy: A multidisciplinary study. International Journal of Science Education, 36, 1-23. doi: 10.1080/09500693.2012.714512

Landis, R. J., \& Koch, G. K. (1977). The measurement of observer agreement for categorical data. Biometrics, 33, 159-174. doi: 10.2307/2529310

Leach, J., Driver, R., Scott, P., \& Woo-Robinson, C. (1996). Children's ideas about ecology 2: Ideas found in children aged 5-16 about the cycling of matter. International Journal of Science Education, 18, 19-34. doi: 10.1080/0950069960180102

Lin, C.-Y., \& Hu, R. (2003). Students' understanding of energy flow and matter cycling in the context of the food chain, photosynthesis, and respiration. International Journal of Science Education, 25, 1529-1544. doi: 10.1080/0950069032000052045

Liu, X., \& Tang, L. (2004). The progression of students' conceptions of energy: A cross-grade, cross-cultural study. Canadian Journal of Science, Mathematics and Technology Education, 4, 43-57. doi: 10.1080/ 14926150409556596

Markl, J. (Ed.). (2010). Markl Biologie Oberstufe [Markl biology for upper secondary school]. Stuttgart, Germany: Ernst Klett.

Mayer, R. E. (2011). Instruction based on visualizations. In Mayer, R. E. \& Alexander, P. A. (Eds.), Handbook of research on learning and instruction (pp. 427-445). New York: Routledge Chapman \& Hall.

Métioui, A., Matoussi, F., \& Trudel, L. (2016). The teaching of photosynthesis in secondary school: A history of the science approach. Journal of Biological Education, 50, 275-289. doi: 10.1080/00219266.2015.1085427

Needham, R. (2014). Using "energy ideas" in the teaching of biology. School Science Review, 96, 74-77.

Nesher, P. (1987). Towards an instructional theory 7: The role of student's misconceptions. For the Learning of Mathematics, 7, 33-40.

Neubrand, C., Borzikowsky, C., \& Harms, U. (2016). Adaptive prompts for learning evolution with worked examples-Highlighting the students between the "novices" and the "experts" in a classroom. International Journal of Environmental \& Science Education, 11, 6774-6795.

Neubrand, C., \& Harms, U. (2017). Tackling the difficulties in learning evolution: Effects of adaptive self-explanation prompts. Journal of Biological Education, 51(4), 336-348. doi: 10.1080/00219266.2016.1233129

Opitz, S. T., Harms, U., Neumann, K., Kowalzik, K., \& Frank, A. (2015). Students' energy concepts at the transition between primary and secondary school. Research in Science Education, 45, 691-715. doi: 10.1007/ s11165-014-9444-8

Opitz, S. T., Neumann, K., Bernholt, S., \& Harms, U. (2017). Students' energy understanding across biology, chemistry, and physics contexts. Research in Science Education. https://doi.org/10.1007/s11165-017-9632-4

Organisation for Economic Co-operation and Development. (2010). PISA computer-based assessment of student skills in science. Paris, France.

Oser, F., Hascher, T., \& Spychiger, M. (1999). Lernen aus Fehlern. Zur Psychologie des "negativen" Wissens [Learning from errors. On the psychology of "negative" knowledge]. In Althof, W. (Ed.), Fehlerwelten. Vom Fehlermachen und Lernen aus Fehlern (pp. 11-41). Opladen, Germany: Leske + Budrich.

Oser, F., Näpflin, C., Hofer, C., \& Aerni, P. (2012). Towards a theory of negative knowledge (NK): Almost-mistakes as drivers of episodic memory 
amplification. In Bauer, J., \& Harteis, C. (Eds.), Human fallibility. The ambiguity of errors for work and learning (pp. 53-70). Dordrecht, Netherlands: Springer.

Oser, F., \& Spychiger, M. (2005). Lernen ist schmerzhaft. Zur Theorie des negativen Wissens und zur Praxis der Fehlerkultur [Learning is painful: The theory of negative knowledge and the use of error culture]. Weinheim, Germany: Beltz.

Özay, E., \& Öztaş, H. (2003). Secondary students' interpretations of photosynthesis and plant nutrition. Journal of Biological Education, 37, 68-70. doi: 10.1080/00219266.2003.9655853

Özkan, Ö., Tekkaya, C., \& Geban, Ö. (2004). Facilitating conceptual change in students' understanding of ecological concepts. Journal of Science Education and Technology, 13, 95-105. doi: 10.1023/ B:JOST.0000019642.15673.a3

Peeck, J. (1989). Trends in the delayed use of information from an illustrated text. In Mandl, H., \& Levin, J. R. (Eds.), Knowledge acquisition from text and pictures (pp. 263-277). Amsterdam: Elsevier.

Posner, G. J., Strike, K. A., Hewson, P. W., \& Gertzog, W. A. (1982). Accommodation of a scientific conception: Toward a theory of conceptual change. Science Education, 66, 211-227. doi: 10.1002/sce.3730660207

Rapp, D. N. (2005). Mental models: Theoretical issues for visualizations in science education. In Gilbert, J. K. (Ed.), Visualization in science education (pp. 43-60). Dordrecht, Netherlands: Springer

Roth, W.-M., Pozzer-Ardenghi, L., \& Han, J. Y. (2005). Critical graphicacy: Understanding visual representation practices in school science. Dordrecht, Netherlands: Springer.

Ryoo, K., \& Linn, M. C. (2012). Can dynamic visualizations improve middle school students' understanding of energy in photosynthesis? Journal of Research in Science Teaching, 49, 218-243. doi: 10.1002/tea.21003

Sadler, P. M., Coyle, H., Smith, N. C., Miller, J., Mintzes, J., Tanner, K., \& Murray, J. (2013). Assessing the life science knowledge of students and teachers represented by the $\mathrm{K}-8$ national science standards. CBE-Life Sciences Education, 12, 553-575. doi: 10.1187/cbe.12-06-0078

Schnotz, W., \& Bannert, M. (2003). Construction and interference in learning from multiple representation. Learning and Instruction, 13, 141-156. doi 10.1016/S0959-4752(02)00017-8

Smith, J. P., diSessa, A. A., \& Roschelle, J. (1993). Misconceptions reconceived: A constuctivist analysis of knowledge in transition. Journal of the Learning Sciences, 3, 115-163. doi: 10.1207/s15327809jls0302_1

Solomon, J. (1983). Messy, contradictory and obstinately persistent: A study of children's out-of-school ideas about energy. School Science Review. $65,225-229$

Stark, R., Kopp, V., \& Fischer, M. R. (2011). Case-based learning with worked examples in complex domains: Two experimental studies in undergrad uate medical education. Learning and Instruction, 21, 22-33. doi: 10.1016/j.learninstruc.2009.10.001
Steuer, G., \& Dresel, M. (2015). A constructive error climate as an element of effective learning environments. Psychological Test and Assessment Modeling, 57, 262-275.

Stoy, P. C. (2010). Thermodynamic approaches to ecosystem behaviour: Fundamental principles with case studies from forest succession and management. In Raffaelli, D. G., \& Frid, C. L. J. (Eds.), Ecosystem ecology. A new synthesis (pp. 40-64). New York: Cambridge University Press.

Tippett, C. D. (2010). Refutation text in science education: A review of two decades of research. International Journal of Science and Mathematics Education, 8, 951-970. doi: 10.1007/s10763010-9203-x

Trumper, R. (1993). Children's energy concepts: A cross-age study. International Journal of Science Education, 15, 139-148. doi: 10.1080/ 0950069930150203

Trussell, G. C., Ewanchuk, P. J., \& Matassa, C. M. (2006). The fear of being eaten reduces energy transfer in a simple food chain. Ecology, 87, 29792984. doi: 10.1890/0012-9658(2006)87[2979:TFOBER]2.0.CO;2

Tsui, C.-Y., \& Treagust, D. F. (2013). Introduction to multiple representations: Their importance in biology and biological education. In Treagust, D. F., \& Tsui, C.-Y. (Eds.), Multiple representations in science education (pp. $3-$ 18). Dordrecht, Netherlands: Springer.

Van den Broek, P., \& Kendeou, P. (2008). Cognitive processes in comprehension of science texts: The role of co-activation in confronting misconceptions. Applied Cognitive Psychology, 22, 335-351. doi: 10.1002/acp.1418.

Van Heuvelen, A., \& Zou, X. (2001). Multiple representations of work-energy processes. American Journal of Physics, 69, 184-194. doi: 10.1119/ 1.1286662

Weidenmann, B. (1989). When good pictures fail: An information-processing approach to the effect of illustrations. In Mandl, H., \& Levin, J. R. (Eds.) Knowledge acquisition from text and pictures (pp. 157-170). Amsterdam Elsevier.

Wernecke, U., Schwanewedel, J., Schütte, K. \& Harms, U. (2016). Wie wird Energie im Biologieschulbuch dargestellt? Entwicklung eines Kategoriensystems und exemplarische Anwendung auf eine Schulbuchreihe [How is energy represented in biology textbooks? Development of a category system and its application to a textbook series]. Zeitschrift für Didaktik der Naturwissenschaften, 22, 215-229. doi: 10.1007/s40573 $-016-00512$

Winn, W. (1989). The design and use of instructional graphics. In Mandl, H., \& Levin, J. R. (Eds.), Knowledge acquisition from text and pictures (pp. 125144). Amsterdam: Elsevier.

World Energy Council. (2015). World Energy Trilemma. Priority Actions on Climate Change and How to Balance the Trilemma. Retrieved November 30, 2016, from www.worldenergy.org/wp-content/uploads/2015/05/ 2015-World-Energy-Trilemma-Priority-actions-on-climate-change -and-how-to-balance-the-trilemma.pdf 